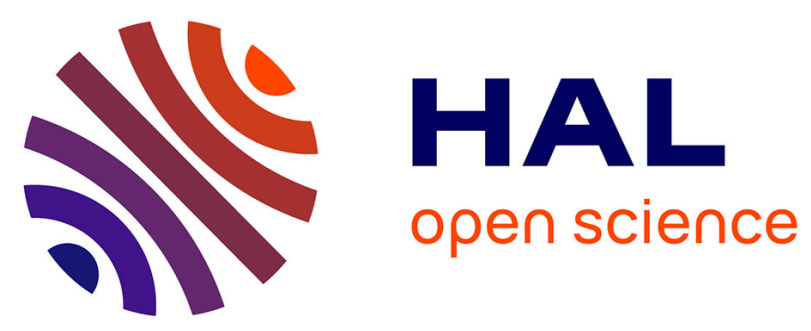

\title{
Porous RuOxNySz Electrodes for Microsupercapacitors and Microbatteries with Enhanced Areal Performance
}

Sai Gourang Patnaik, Jensheer Shamsudeen Seenath, David Bourrier, Sagar Prabhudev, Daniel Guay, David Pech

\section{- To cite this version:}

Sai Gourang Patnaik, Jensheer Shamsudeen Seenath, David Bourrier, Sagar Prabhudev, Daniel Guay, et al.. Porous RuOxNySz Electrodes for Microsupercapacitors and Microbatteries with Enhanced Areal Performance. ACS Energy Letters, 2021, 6, pp.131-139. 10.1021/acsenergylett.0c02017 . hal03063689

\section{HAL Id: hal-03063689 \\ https://hal.science/hal-03063689}

Submitted on 14 Dec 2020

HAL is a multi-disciplinary open access archive for the deposit and dissemination of scientific research documents, whether they are published or not. The documents may come from teaching and research institutions in France or abroad, or from public or private research centers.
L'archive ouverte pluridisciplinaire HAL, est destinée au dépôt et à la diffusion de documents scientifiques de niveau recherche, publiés ou non, émanant des établissements d'enseignement et de recherche français ou étrangers, des laboratoires publics ou privés. 


\title{
Porous $\mathrm{RuO}_{\mathrm{x}} \mathrm{N}_{\mathrm{y}} \mathrm{S}_{\mathrm{z}}$ Electrodes for Microsupercapacitors and Microbatteries with Enhanced Areal Performances
}

\author{
Sai Gourang Patnaik, ${ }^{\dagger}$ Jensheer Shamsudeen Seenath, ${ }^{\dagger}$ David Bourrier ${ }^{\dagger}$ Sagar Prabhudev,${ }^{\ddagger}$ Daniel \\ Guay, ${ }^{\ddagger}$ and David Pech*,† \\ 'LAAS-CNRS, Université de Toulouse, CNRS, 7 avenue du colonel Roche, 31400 Toulouse, France. \\ ¥INRS-Énergie, Matériaux et Télécommunications, 1650 boulevard Lionel Boulet, Varennes, Québec J3X 1P7, Canada.
}

\begin{abstract}
Three-dimensional electrodes with improved areal energy have become increasingly important for microscale energy storage at the dawn of the Internet of Things. At its heart are plethora of microelectronic devices that require embedded energy harvesters and energy storage components to ensure autonomy. In this study, we develop porous metallic microstructures and their conformal coating with a new $\mathrm{RuO}_{\mathrm{x}} \mathrm{N}_{\mathrm{y}} \mathrm{S}_{\mathrm{z}}$ material through facile optimized electrodeposition process. The microporous structure with nanodendritic network shows high areal capacitance $\left(14.3 \mathrm{~F} \mathrm{~cm}^{-2}\right.$ for the electrode and $714 \mathrm{mF}^{-2}$ for an all-solid-state microsupercacitor) and stable performance ( $>80 \%$ retention after 5000 cycles) towards $\mathrm{H}^{+}$storage. Remarkable $\mathrm{Li}^{+}$storage capability with high areal capacity $\left(5 \mathrm{mAh} \mathrm{cm} \mathrm{cm}^{-2}\right)$ and rate characteristics $\left(1.5 \mathrm{mAh} \mathrm{cm}^{-2}\right.$ at $\left.3 \mathrm{C}\right)$ is also observed. These results coupled with facile synthetic strategy can thus offer inspiration for large-scale production of 3D porous electrodes for microbatteries and microsupercapacitors.
\end{abstract}

Demand for miniaturized electronic systems have seen tremendous growth in the last few decades, thanks to rapid advances in micro and nanofabrication technologies. These tiny systems are ubiquitous: implantable sensors, microelectromechanical systems, wearable electronics, medical equipment's, radio-frequency identification (RFID) tag, environment monitoring systems, Internet of Things (IoT) based applications etc. But with this growing sophistication, efficient energy solutions are equally imperative to fuel up the associated power electronics. The need of the hour is to maximize output power from limited footprint area in order for these energy storage devices to be integrated directly into the circuit boards instead through external connections that lead to ohmic losses. Microbatteries (MBs) $)^{1,2}$ and microsupercapacitors (MSCs) $)^{3-5}$ have been extensively proposed and utilized in many miniaturized systems coupled with efficient energy harvesters ${ }^{6-8}$. However, to satiate the ever-hungry power electronics, novel electrode architectures and multifunctional materials design and engineering are necessary. The primary challenge is to overcome the hurdle of limited areal capacity of existing microenergy storage devices. While MB's have been successful to some extent, they lack to provide high capacity at high operating potentials from limited footprint area. Also, they are primarily energy delivery devices with low power and limited life cycle. MSC's circumvent these issues with excellent cyclability and power characteristics, but have mediocre energy density. Even though both these classes of energy storage devices are complimentary to each other, numerous challenges still remain to be addressed in each category for wide scale integration into microelectronic systems. Since areal/volume specific capacity is important in microsystems, it is essential to screen appropriate materials which are apt for the purpose. 3D structure has been well exploited to enhance capacity from limited footprint area in microbatteries and microsupercapacitors in the past. However, a major bottleneck is inability to achieve conformal deposition of active materials on the 3D scaffolds, which limits utilization of their full potential. Hence, in pursuit of achieving superlative performance metrics, we try to conformally deposit active materials on highly porous 3D electrodes under ambient conditions. The choice of material in this case was a novel hydrous $\mathrm{RuO}_{\mathrm{x}} \mathrm{N}_{\mathrm{y}} \mathrm{S}_{\mathrm{z}}$-based material.

Ruthenium dioxide is well known to possess extremely high specific pseudocapacitance owing to its ability to undergo rapid redox reactions with its multiple valence states in a reversible manner ${ }^{9-11}$. In addition, it also possesses excellent electronic conductivity which is essential for a stable microbattery/supercapacitor electrode with low overall impedance. Owing to such interesting properties, many groups have tried to incorporate $\mathrm{RuO}_{2}$ in different interesting configurations to tap its enormous potential in supercapacitor ${ }^{12-}$

${ }^{14}$ as well as in battery ${ }^{15,16}$ based applications. In the present study, a new ruthenium oxide-based material was chosen as the material for fabrication of high energy/power electrodes for micro-energy storage devices with excellent stability and rate performance. Controlled electrodeposition of sheet like hydrous $\mathrm{RuO}_{\mathrm{x}} \mathrm{N}_{\mathrm{y}} \mathrm{S}_{\mathrm{z}}$ material on porous $3 \mathrm{D}$ architectures was achieved through carefully optimized parameters and studies for high performance MSCs and MBs are reported. The presence of heteroatoms like N and S in $\mathrm{RuO}_{\mathrm{x}}$ framework not only affect the microstructure and surface area but also can be beneficial in providing better access to active sites in supercapacitors ${ }^{17}$. In batteries, presence of these heteroatoms can enhance electrolyte wettability ${ }^{18}$. For MSCs, the performance of porous $\mathrm{RuO}_{\mathrm{x}} \mathrm{N}_{\mathrm{y}} \mathrm{S}_{\mathrm{z}}$ material was thus evaluated towards surface $\mathrm{H}^{+}$ion storage through pseudocapacitance at low potential (0.10$0.95 \mathrm{~V}$ vs. SCE) as a power delivery device. In MBs, its response towards $\mathrm{Li}^{+}$storage was studied at high potential range $(0.75-3.5$ $\mathrm{V}$ vs. $\mathrm{Li} / \mathrm{Li}^{+}$) as an energy storage source. We report record specific capacitance of $>10 \mathrm{~F} \mathrm{~cm}^{-2}$ for MSC electrodes and $>5 \mathrm{mAh} \mathrm{cm}^{-}$ 2 for $\mathrm{MBs}$, thereby projecting these $3 \mathrm{D}$ porous electrodes as promising candidates for fueling next generation miniaturized microelectronics. 
(a)

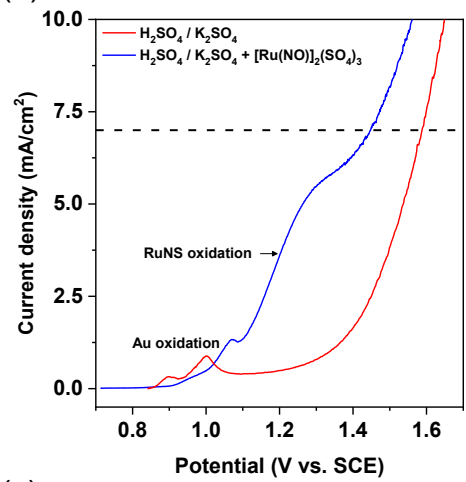

(c)

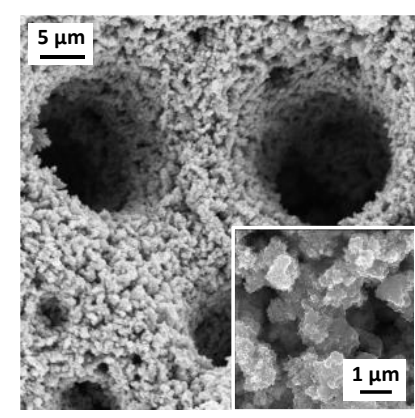

(b)

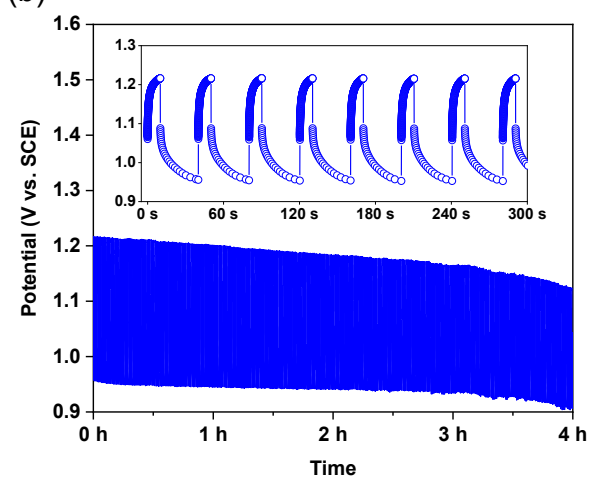

(d)

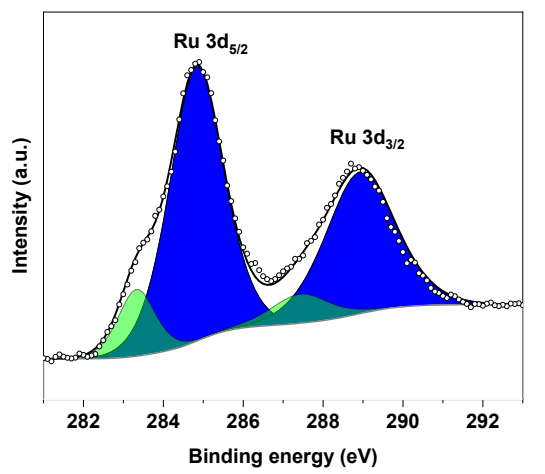

Figure 1. Material synthesis and characterization. (a) Linear sweep voltammetry (LSV) studies showing different interfacial processes during potential scan. (b) Evolution of potential time curve during 4 hours of deposition. (c) SEM micrographs at different magnifications after 4 hours of deposition. (d) Ru-3d core-level XPS spectrum of the deposited material.

Highly porous metallic current collectors were first prepared using the dynamic hydrogen bubble template (DHBT) method on a silicon substrate. DHBT is advantageous in terms of its cleanliness, simplicity, and ease of preparation, making it easily transferable to pilot production line in microelectronic facilities. Such porous metallic current collectors are also ideally suited for attaching pseudocapacitive materials like $\mathrm{RuO}_{2}$, reported before by our group ${ }^{19,20}$ and also by other workers ${ }^{21}$. DHBT was thus used to prepare highly porous gold architectures onto which novel hydrous $\mathrm{RuO}_{\mathrm{x}}$-based material was electrodeposited for MSCs and subsequently water was got rid of for $\mathrm{MB}$ application. Electrodeposition of hydrous $\mathrm{RuO}_{2}$ has been evaluated in the past by different techniques including cyclic voltammetry ${ }^{22}$, anodic ${ }^{23}$ and cathodic $^{24}$ polarization in static as well as pulsed configurations. Out of all the techniques, pulsed techniques provided best results for supercapacitive applications ${ }^{25}$. Even though one can envisage pulsed potential methods to be more controllable, pulsed current configurations are more versatile as they can be easily scaled up industrially without utilizing a reference electrode. Hence, we investigated pulsed current technique for conformal electrodeposition of hydrous $\mathrm{RuO}_{x}-$ based material on porous $\mathrm{Au}$ substrates. In addition, the majority of the reported protocols have utilized $\mathrm{RuCl}_{3}$ based precursors, mostly because of its well understood chemistry in aqueous media ${ }^{26}$. However, $\mathrm{RuCl}_{3}$ was not compatible with the porous $\mathrm{Au}$ substrates prepared by DHBT due to high potential complexation of $\mathrm{Cl}^{-}$with Au (Figure S1) and hence, we screened several other salts and chose $[\mathrm{Ru}(\mathrm{NO})]_{2}\left(\mathrm{SO}_{4}\right)_{3}$ for plating hydrous $\mathrm{RuO}_{\mathrm{x}} \mathrm{N}_{\mathrm{y}} \mathrm{S}_{\mathrm{z}}$. The linear sweep voltammetry (LSV) profile of the Au current collector in electrolyte bath showed two different interfacial processes, initial gold oxidation peak (conspicuous in the solution even without the Ru salt) followed by oxidation of nitrosyl sulfate (NS) salt-precursor (Figure 1a). The current for pulse was chosen so as to cover both these processes. A galvanostatic pulse of $7 \mathrm{~mA} \mathrm{~cm}^{-2}$ for $10 \mathrm{~s} \mathrm{(optimized} \mathrm{for} \mathrm{porous} \mathrm{substrates} \mathrm{from} \mathrm{LSV} \mathrm{studies)} \mathrm{was}$ followed by a rest period of $30 \mathrm{~s}$ to stabilize/equilibrate the porous structure/electrolyte interface (Figure $1 \mathrm{~b}$ ). The total pulse time determined the actual content of $\mathrm{RuO}_{\mathrm{x}} \mathrm{N}_{\mathrm{y}} \mathrm{S}_{\mathrm{z}}$ on the substrates and increased pulse-on period depositions $(1 \mathrm{~h}, 2 \mathrm{~h}, 3 \mathrm{~h}$ etc $)$ were performed to have higher active material loading. The bare porous gold structure had a thickness of $\sim 50-60 \mu \mathrm{m}$ and the samples with the highest loading (1440 pulses, i.e. 4 hours pulse-on) had a thickness of $\sim 160 \mu \mathrm{m}$. Figure 1c shows the microstructure of the deposited samples which have the original DHBT structure retained but with flaky $\mathrm{RuO}_{\mathrm{x}}$-based deposits over the dendritic Au structure. However, it is interesting to note here that, even after 20 hours of electrodeposition (i.e. 5 hours pulse-on), neither the large pores nor even the smallest pores of the porous substrates are blocked by the active material. Such conformal deposition is essential to fully utilize the advantages of 3D nanostructure and to achieve higher energy density. Elemental mapping through energydispersive X-ray (EDX) analysis further confirmed conformal deposition of the Ru-based active material over the entire porous Au structure below (Figure S2).

X-ray photoelectron spectroscopy (XPS) studies were performed to probe the chemical nature of the deposited film (Figures 1d, S3 and S4). These measurements were compared with XPS performed on NS salt-precursor (Figure S5) and a crystalline- $\mathrm{RuO}_{2}$ 
reference obtained from a well-defined $\mathrm{RuO}_{2}$ (001) thin-film that we synthesized by pulsed laser deposition (PLD), (Figure S6). Although the XPS spectrum shows presence of nitrogen and sulfur in the film (even after heat-treatment), the Ru-3d, N-1s and S-2p core-level spectra of the deposited material exhibited a very different chemical signature from the initial NS salt-precursor. From Ru3d, Ru-3p, O-1s, N-1s and S-2p core level spectra (see the Supporting Information for quantification details), the surface composition of the as-deposited and heat-treated sample was estimated to be 9 at.\% Ru, 76 at.\% O, 12 at.\% $\mathrm{N}$ and 3 at.\% S. However, the distinctiveness in the detailed XPS spectra makes it clear that the deposited material is more closely related a $\mathrm{RuO}_{2}$-based material with the following composition $\mathrm{RuO}_{\mathrm{x}} \mathrm{N}_{\mathrm{y}} \mathrm{S}_{\mathrm{z}}$ that is distinctively different from the NS salt-precursor used for the synthesis. This is further confirmed by the noticeable pseudocapacitive behaviour of this material in the electrochemical analysis hereafter.

(a)

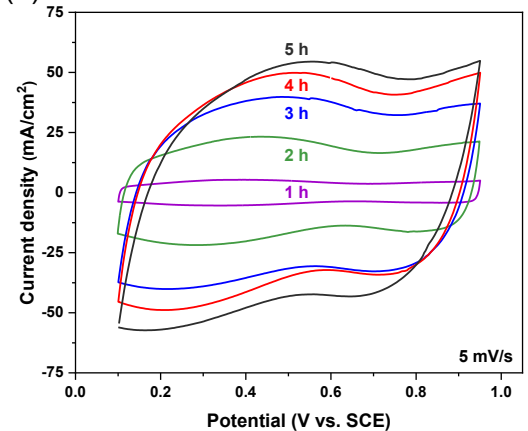

(d)

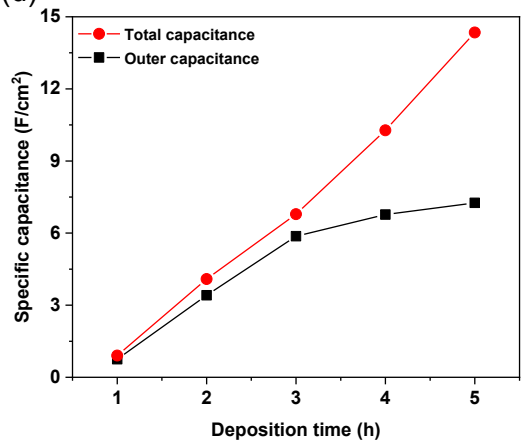

(b)

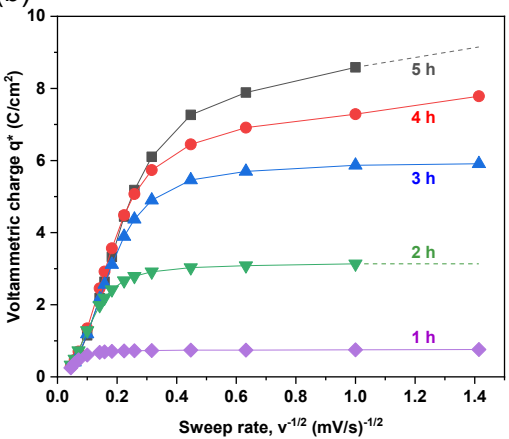

(e)

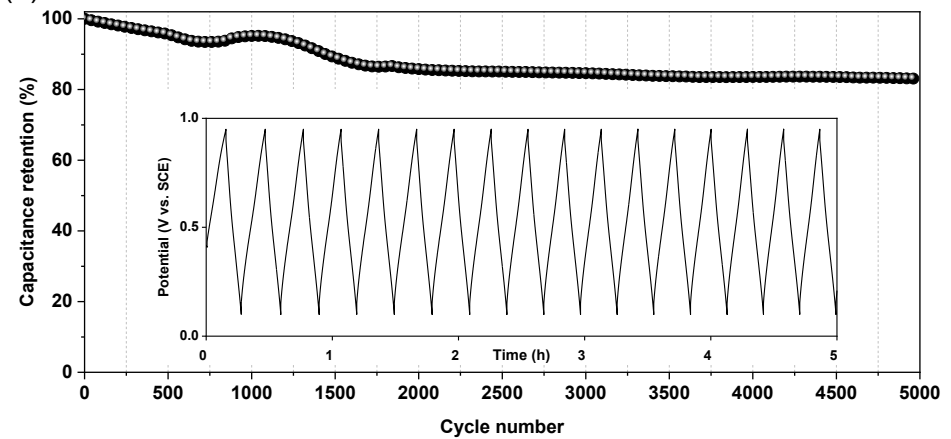

(c)

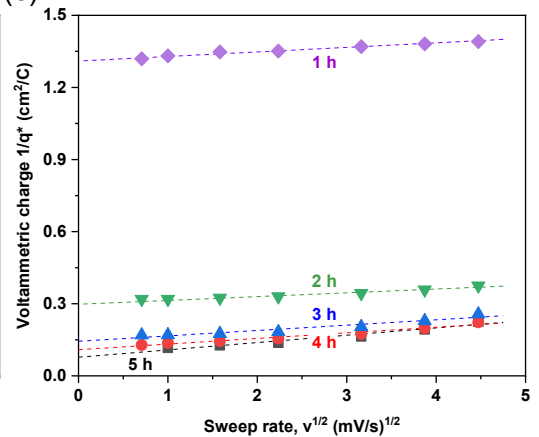

Figure 2. Porous $\mathrm{RuO}_{\mathrm{x}} \mathrm{N}_{\mathrm{y}} \mathrm{S}_{\mathrm{z}}$ as microsupercapacitor electrode. (a) Cyclic voltammetry profiles of electrodes after different deposition durations in $0.5 \mathrm{M} \mathrm{H}_{2} \mathrm{SO}_{4}$. (b) Determination of the outer charge, $q_{\text {outer }}$, of different electrodes obtained by calculating average voltammetric charge, $q^{*}$, as a function of sweep rate $v$. (c) Determination of the total charge, $q_{\text {total }}$, of the electrodes using inverse of voltammetric charge versus square root of sweep rate plots. (d) Evolution of total capacitance, $C_{t}$, and outer capacitance, $C_{o}$, after different deposition durations. (e) Stability of the electrode ( $3 \mathrm{~h}$ deposition) during long-term galvanostatic charge discharge (GCD) studies and corresponding potential time profiles at $10 \mathrm{~mA} \mathrm{~cm}^{-2}$.

We first studied the electrochemical performance for supercapacitive applications in three-electrode configuration in $0.5 \mathrm{M} \mathrm{H}_{2} \mathrm{SO}_{4}$. To optimize the capacitive performance of porous $\mathrm{RuO}_{\mathrm{x}} \mathrm{N}_{\mathrm{y}} \mathrm{S}_{\mathrm{y}}$, different pulse durations during the deposition step were explored. Figure 2a shows representative cyclic voltammograms (CVs) for capacitive performances of different samples with increased active material loadings. Higher specific capacitance was observed with increase of active materials, while retaini ng the capacitive profile at a given scan rate. The electrode exhibits an extremely high capacitance of $8.5 \mathrm{~F} \mathrm{~cm}^{-2}$ when cycled at $5 \mathrm{mV} \mathrm{s}^{-1}$, which is to our knowledge the highest value ever reported for a microsupercapacitor electrode. The electrochemical impedance spectroscopic studies showed a vertical line in the lower frequency region with a negligible semicircle at higher frequencies related to charge transfer resistance, further proving the pseudocapacitive behavior of the electrodes (see Nyquist plot in Figure S7). We also performed CV studies at different sweep rates (from 0.5 to $500 \mathrm{mV} \mathrm{s}^{-1}$ ) to understand charge accessibility in different samples (Figures $2 \mathrm{~b}, \mathrm{c}$ ). By systematically varying the loading, we could achieve a record value of $\sim 14.3 \mathrm{~F} \mathrm{~cm}^{-2}$ for 5 hours of total pulse-on time deposition (Figure $2 \mathrm{~d}$ ). Outer charge contribution $\left(q_{\text {outer }}\right)$ accounted for more than $80 \%$ of the total charge stored $\left(q_{\text {total }}\right)$, indicating most of the deposited material to be directly in contact with the electrolyte. However, the difference between the $q_{\text {outer }}$ and $q_{\text {total }}$ curves progressively started to increase upon increasing the deposition time, indicating relatively lower charge accessibility in thicker layers of $\mathrm{RuO}_{\mathrm{x}} \mathrm{N}_{\mathrm{y}} \mathrm{S}_{\mathrm{z}}$ albeit overall higher specific capacitance. The areal capacitance of the porous electrodes with better charge accessibility (3 h pulse-on deposition) was also evaluated using galvanostatic charge discharge (GCD) studies (Figure S8). GCD profiles at different current densities exhibited small voltage hysteresis between charge and discharge, characteristic of pseudocapacitive materials ${ }^{27}$. The areal capacitance of the microsupercapacitor electrode, taken from the GCD curve was calculated to be $6.6 \mathrm{~F} \mathrm{~cm}^{-2}$ at a current density $10 \mathrm{~mA} \mathrm{~cm}^{-2}$, and $5.0 \mathrm{~F} \mathrm{~cm}^{-2}$ at a current density of $100 \mathrm{~mA} \mathrm{~cm}^{-2}$, thus retaining $75 \%$ of initial capacitance even after ten times increase in current. The long-term behavior of the electrode was tested by repeated galvanostatic charge/discharge cycles at high current of $10 \mathrm{~mA} \mathrm{~cm}^{-2}$ (Figure 2e). The cycling experiment indicates excellent stability of the porous electrodes with more than $80 \%$ retention of the initial capacitance after 5000 cycles. To our knowledge, such high area specific capacitance with excellent 
stability has not been reported with $3 \mathrm{D}$ electrodes in the past for $\mathrm{RuO}_{2}$ based materials. Application of this strategy in full 3D interdigitated devices will be particularly interesting for high energy microsupercapacitors in various niche areas. Encouraged with such superior performance, we wanted further to explore the feasibility of $\mathrm{Li}^{+}$ion storage at high potentials w.r.t to $\mathrm{Li} / \mathrm{Li}^{+}$into porous $\mathrm{RuO}_{\mathrm{x}} \mathrm{N}_{\mathrm{y}} \mathrm{S}_{\mathrm{z}}$ electrodes as potential microbattery cathodes.

(a)

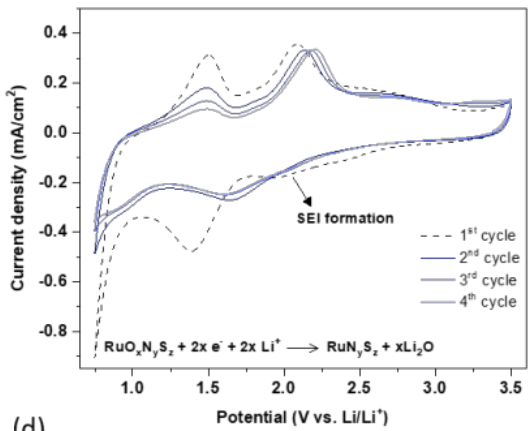

(d)

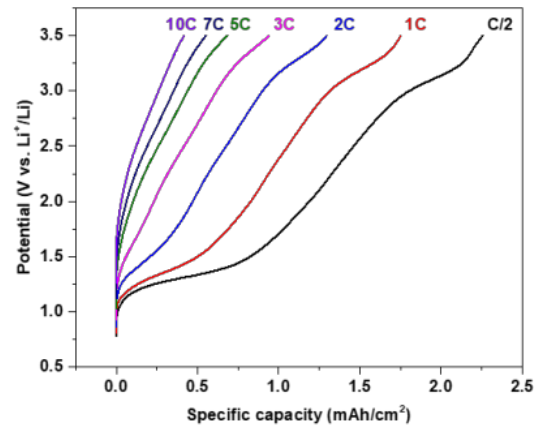

(b)

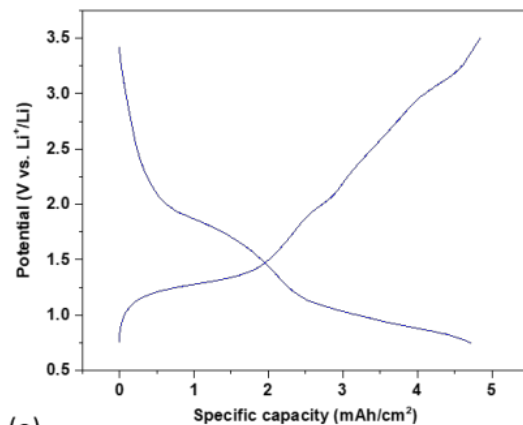

(e)

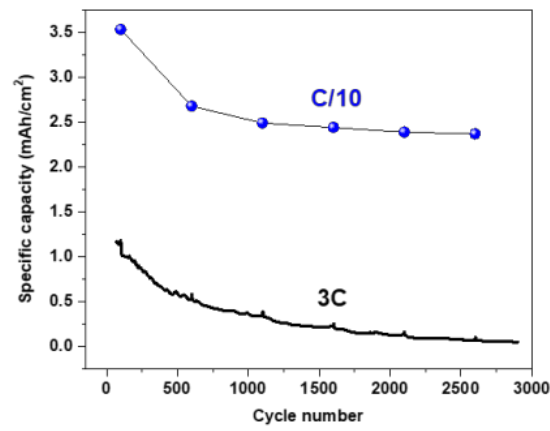

(c)

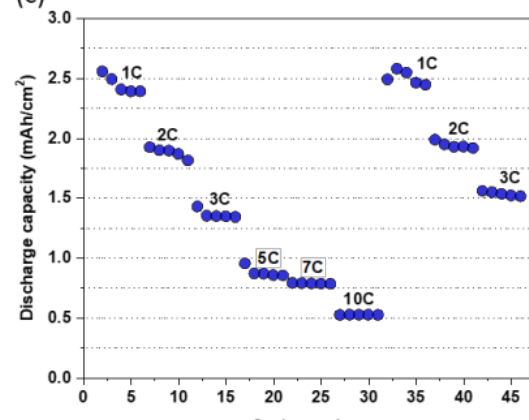

(f)

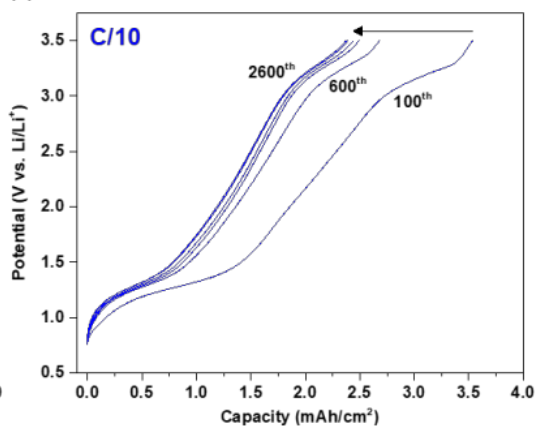

Figure 3. Porous $\mathrm{RuO}_{x} \mathrm{~N}_{y} \mathrm{~S}_{z}$ as microbattery electrode. (a) Cyclic voltammetry profiles of electrodes showing lithiation and de-lithiation processes at $0.5 \mathrm{mV} \mathrm{s}^{-1}$. (b) Galvanostatic charge discharge profile at $0.1 \mathrm{~mA} \mathrm{~cm}{ }^{-2}$. (c) Specific capacity retention at different charge discharge rates and (d) corresponding discharge profiles. (e) Reversible capacity retention during long term charge discharge studies at $3 \mathrm{C}$ and at $\mathrm{C} / 10$ (performed every 500 cycles) and (f) corresponding discharge profiles at $\mathrm{C} / 10$ rate.

$\mathrm{RuO}_{2}$ has a theoretical volumetric capacity of $5617 \mathrm{mAh} \mathrm{cm}^{-3}\left(806 \mathrm{mAh} \mathrm{g}^{-1}\right.$, density $\left.=6.97 \mathrm{~g} \mathrm{~cm}^{-3}\right)$ towards $\mathrm{Li}^{+}$ion storage through complex multiphasic mechanism ${ }^{28,29}$ (up to $4 \mathrm{Li}^{+}$per unit, below $0.9 \mathrm{~V}$ vs. $\mathrm{Li} / \mathrm{Li}^{+}$) ${ }^{16}$ with excellent columbic efficiency during the initial cycles ${ }^{29}$. In addition, its metallic conductivity $(36.2 \mu \Omega \mathrm{cm}$ resistivity) and high rate performance are especially elusive for application in microbatteries as Li-free cathodes with high energy density and rate capability. However, typical to conversion-type reactions, it suffers from structural degradation at high rates or upon cycling, thereby limiting its wide scale application ${ }^{30}$. It has been indicated previously that amorphous $\mathrm{RuO}_{2}$ synthesized electrochemically can have better performance in terms of lithiation potential and cycling than bulk $\mathrm{RuO}_{2}{ }^{31}$. In addition, when thin layers $(\sim 100 \mu \mathrm{m})$ of such amorphous material is conformably deposited on sturdy metallic current collectors, their performance can be greatly improved. Hence, we evaluated the electrochemical properties of porous $\mathrm{RuO}_{\mathrm{x}} \mathrm{N}_{\mathrm{y}} \mathrm{S}_{\mathrm{z}}$ towards $\mathrm{Li}^{+}$storage, hoping to take advantage of the large surface area and porous structure for high energy and high power microbatteries.

Since water can be detrimental towards battery performance, the porous $\mathrm{RuO}_{\mathrm{x}} \mathrm{N}_{\mathrm{y}} \mathrm{S}_{\mathrm{z}}$ electrodes were first dried under vacuum at $200^{\circ} \mathrm{C}$ for at least four hours, to get rid of any moisture content. X-ray diffraction (XRD) patterns showed that the sample remains in amorphous state with no crystallization peaks related to rutile-like $\mathrm{RuO}_{2}$, even after heat-treatment at 200 and $225^{\circ} \mathrm{C}(\mathrm{Figure} \mathrm{S} 9$ ). $\mathrm{Li}$ ion cells were then fabricated with $\mathrm{Li}$ foil as counter/reference electrode, commercial electrolyte (LiPF 6 in ethylene carbonate and diethylene carbonate, 1:1 EC:DEC) and porous $\mathrm{RuO}_{\mathrm{x}} \mathrm{N}_{\mathrm{y}} \mathrm{S}_{\mathrm{z}}$ as working electrode. The cell exhibited a stable open circuit voltage of $\sim 3.40 \mathrm{~V}$ after resting (6 hours). CV studies (Figure $3 \mathrm{a}$ ) show a small broad peak at $\sim 2.1 \mathrm{~V} \mathrm{vs.} \mathrm{Li} / \mathrm{Li}^{+}$and a prominent peak at $1.4 \mathrm{~V}$ vs. $\mathrm{Li} / \mathrm{Li}^{+}$during the first lithiation, consistent with previous reports of multistep lithiation ${ }^{29,32}$. The initial redundant broad peak $\left(\sim 2.1 \mathrm{~V}\right.$ vs. $\left.\mathrm{Li} / \mathrm{Li}^{+}\right)$can be due to electrolyte degradation followed by intercalation to form $\mathrm{LiRuO}_{\mathrm{x}} \mathrm{N}_{\mathrm{y}} \mathrm{S}_{\mathrm{z}}$ type species and further conversion to $\mathrm{Li}_{2} \mathrm{O}$ and $\mathrm{RuN}_{\mathrm{y}} \mathrm{S}_{\mathrm{z}}$ type amorphous phases. The delithiation process occurs in two steps with peak potentials at 1.5 and $2.0 \mathrm{~V}$ vs. $\mathrm{Li} / \mathrm{Li}^{+}$, corresponding to reformation of $\mathrm{LiRuO}_{x} \mathrm{~N}_{y} \mathrm{~S}_{\mathrm{z}}$ type species and regeneration of $\mathrm{RuO}_{x} \mathrm{~N}_{y} \mathrm{~S}_{\mathrm{z}}$, respectively. In the subsequent cycles, similar behavior is retained except for solid-electrolyte interface (SEI) formation, thus indicating that presence of heteroatoms (like $\mathrm{N}, \mathrm{S}$ ) or the deposition methodology doesn't drastically affect the electrochemical behavior towards reversible $\mathrm{Li}^{+}$ ion storage as compared to widely studied $\mathrm{RuO}_{2}$ which also exhibits similar stepwise lithiation and delithiation processes. This was also reflected in galvanostatic charge discharge profiles. Due to extremely porous structure, stable reversible capacity as high as $5 \mathrm{mAh} \mathrm{cm}^{-2}$ could be achieved at low $\mathrm{C}$ rates (Figure $3 \mathrm{~b}$ ). The porous structure along with intrinsic high rate capability of $\mathrm{RuO}_{\mathrm{x}} \mathrm{N}_{\mathrm{y}} \mathrm{S}_{\mathrm{z}}$ was well reflected in rate studies (Figure $3 \mathrm{c}$ ), with reversible capacity $>0.5 \mathrm{mAh} \mathrm{cm}{ }^{-2}$ at $10 \mathrm{C}$ rate $\left(1 \mathrm{C}=1 \mathrm{~mA} \mathrm{~cm}^{-2}\right)$ and conspicuous two step battery-like profile maintained up to $3 \mathrm{C}$ rate (Figure 3d and S10). Cycling stability studies were also performed on different samples. Significant reversible capacity retention was observed with 3 hours pulse-on deposition for more than 2000 cycles (Figure 
3e). To understand the mechanism for capacity reduction during cycling, impedance measurements were performed at regular intervals during long cycling (at 3C) along with a slow rate cycle (0.1C). The initial electrochemical impedance spectroscopy (EIS) spectrum showed low internal resistance followed by two suppressed semicircles at high frequency region corresponding to SEI and charge transfer resistance respectively (Figure S11). The internal resistance of the cell started to increase with cycling whereas other resistive components saw relatively less change upon cycling. The aging mechanism can thus be related to the progressive degradation of the electrolyte during cycling, and can be easily addressed using solid electrolytes. This was also well observed in the slow rate cycles interspersed between the high rate long cycling studies. The average discharge capacity at $0.1 \mathrm{C}$ remained almost similar at $\sim 2.5 \mathrm{mAh} \mathrm{cm}^{-2}$ even after 2600 cycles (Figure $3 \mathrm{f}$ and S12). Scanning electron microscopy (SEM)/EDX analysis after long cycling (Figures S13 and S14) revealed that the dendritic structure of the porous gold structure was maintained and embedded within electrolyte reduction products, hence further showcasing the plausibility of these porous structures for long life cycle microbatteries with other electrolyte designs.
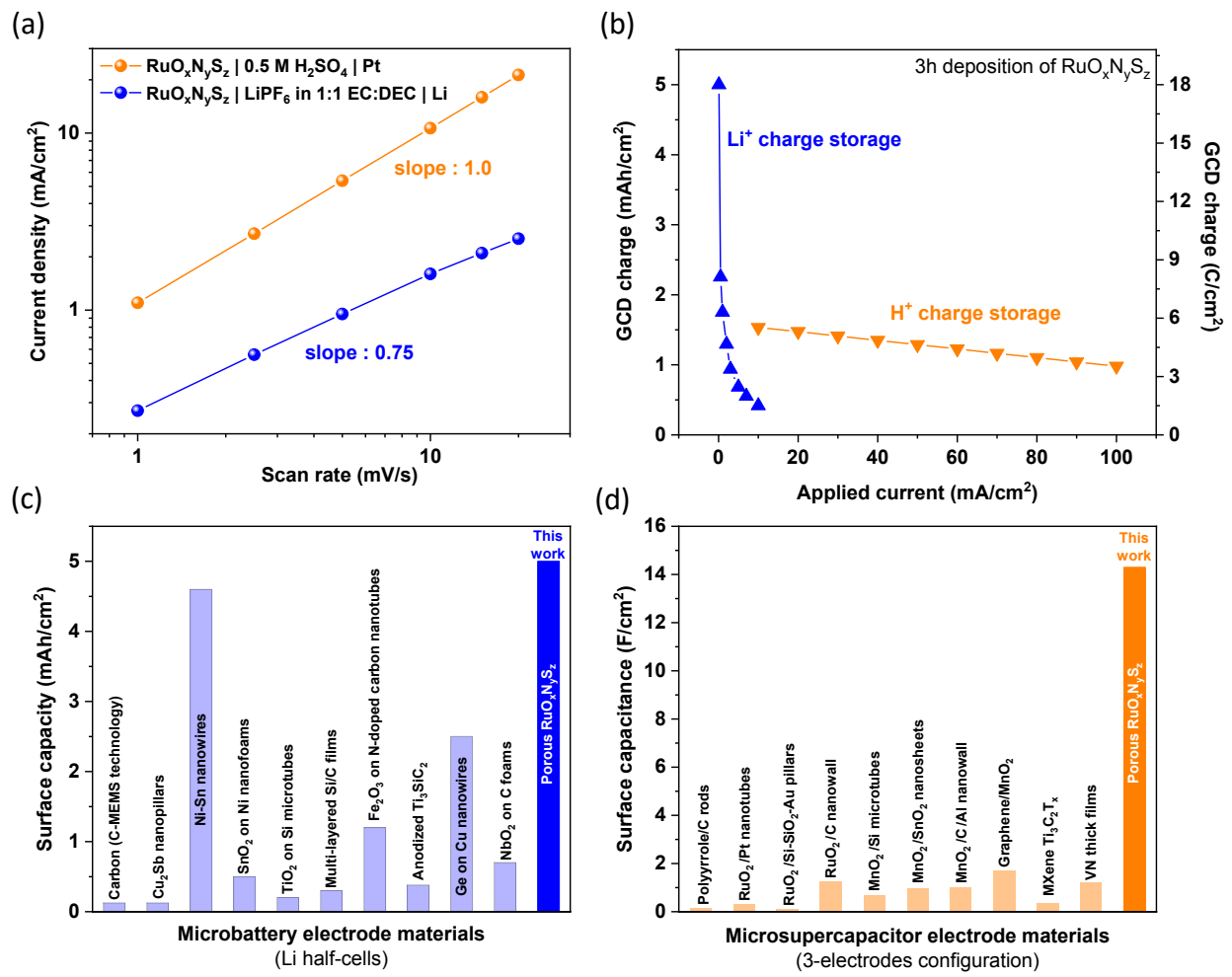

Figure 4. Comparison of porous RuOxNySz as microbattery and microsupercapacitor electrode. (a) Peak current density from CV studies at different scan rate for each case. (b) Charge storage ability as a function of applied current. State-of-the-art (c) microbattery electrode materials (surface capacity) and (d) microsupercapacitor electrode materials (surface capacitance).

We further tried to compare the charge storage performance of porous $\mathrm{RuO}_{x} \mathrm{~N}_{\mathrm{y}} \mathrm{S}_{\mathrm{z}}$, synthesized using the same loading ( 3 hours pulse-on) towards $\mathrm{H}^{+}$and $\mathrm{Li}^{+}$storage. We have considered the sweep-rate dependence of the recorded current, as shown in Figure 4a. A linear dependency between $\log ($ current $i)$ and $\log ($ scan rate $v)$ is observed for both electrolytes $\left(\mathrm{H}_{2} \mathrm{SO}_{4}\right.$ and $\mathrm{LiPF}_{6}$ in EC:DEC). The slope of the $\log (i)$ vs. $\log (v)$ can give an estimate of the mechanisms responsible for the charge storage occurring in the material: if the slope is 0.5 , then the current is diffusion-controlled; if the slope is 1 , then the current is capacitive. As expected, the slope of the $\log (i)$ vs. $\log (v)$ in aqueous sulfuric acid electrolyte is 1 , indicating that the overall response tends to be pseudocapacitive. Using $\mathrm{LiPF}_{6}$ in $\mathrm{EC}: \mathrm{DEC}$, we observe a contribution from the diffusion-controlled process related to $\mathrm{Li}^{+}$insertion with a slope of 0.75 . The comparison of charge storage ability as a function of applied current (Figure $4 \mathrm{~b}$ ) indicates the interaction towards $\mathrm{H}^{+}$to be apt for high power applications whereas the reaction with $\mathrm{Li}^{+}$is more appealing for high energy type requirements. The high areal capacity and durability of porous $\mathrm{RuO}_{x} \mathrm{~N}_{y} \mathrm{~S}_{\mathrm{z}}$ in $\mathrm{Li}^{+}$cells make it a promising $\mathrm{Li}$-free microbattery cathode as compared to other reported metal oxide type active materials (Figure $4 \mathrm{c}$ ) while its performance as supercapacitor electrode also stands out as the highest ever reported areal capacitance $\left(\sim 14 \mathrm{~F} \mathrm{~cm}^{-2}\right)$ to the best of our knowledge (Figure $\left.\left.4 \mathrm{~d}\right)\right)^{3,33,34,43,44,35-42}$

To assess the performance of this electrode material in a microdevice, we created an all-solid-state microsupercapacitor in an interdigitated configuration integrated on a silicon wafer, using a poly(vinyl alcohol) (PVA)-based electrolyte doped with silicotungstic acid $\left(\mathrm{H}_{4} \mathrm{SiW}_{12} \mathrm{O}_{40}, \mathrm{SiWa}\right)$ as well as with [EMIM][TFSI] ionic liquid (1-ethyl-3-methylimidazolium bis(trifluoromethyl sulfonyl) imide) doped with SiWa. A thin metallic Ti/Au sublayer were first patterned onto an oxidized silicon wafer using conventional photolithography and lift-off techniques. Porous gold current collectors were then selectively electrodeposited using the DHBT method onto the conductive areas. The thickness and aspect ratio AR (defined as the ratio of the electrochemically active 
surface area to the geometrical surface area) of the metallic current collector were ca. $30 \mu \mathrm{m}$ and $374 \mathrm{~cm}^{2} \mathrm{~cm}^{-2}$, respectively. RuO $_{\mathrm{x}} \mathrm{N}_{\mathrm{y}} \mathrm{S}_{\mathrm{z}}$ was afterward electrodeposited on the resulting 3D conducting current collector (Figures $5 \mathrm{a}, \mathrm{b}$ ).
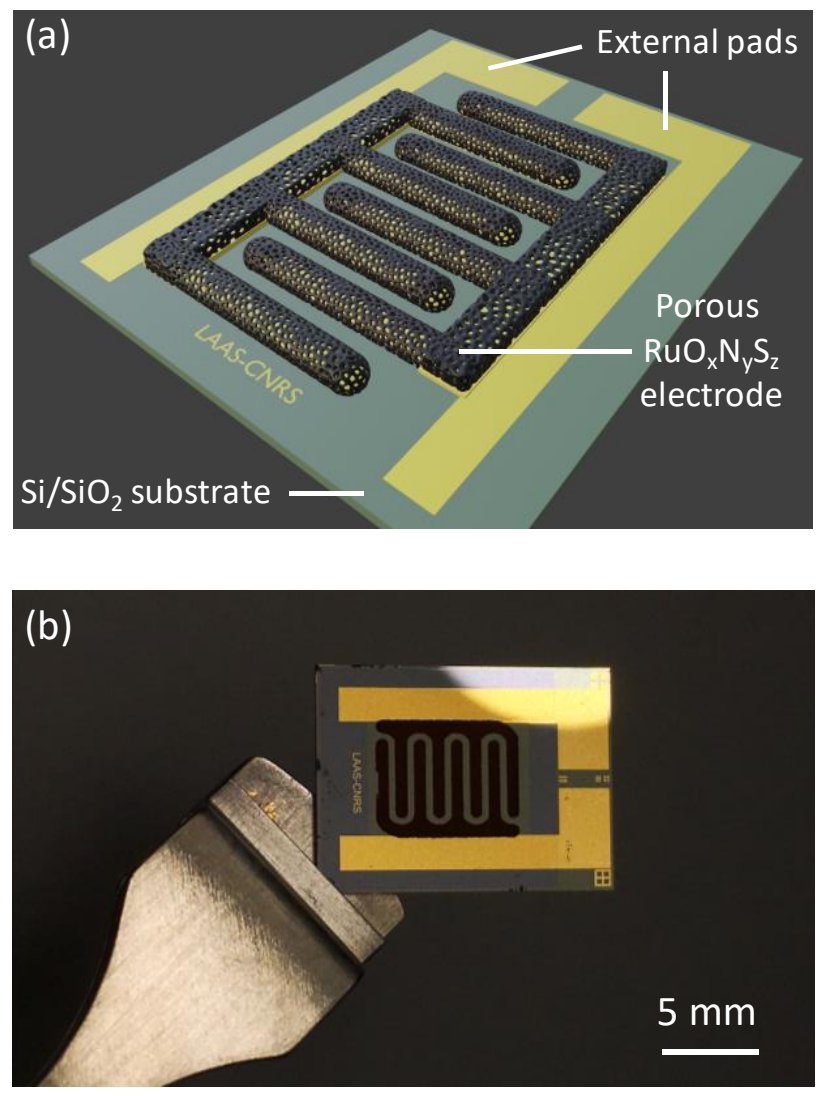

(c)

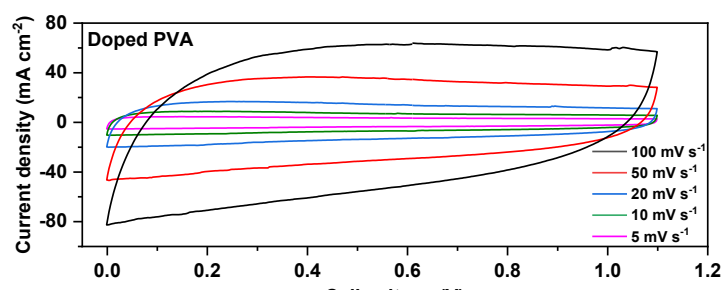

(d)

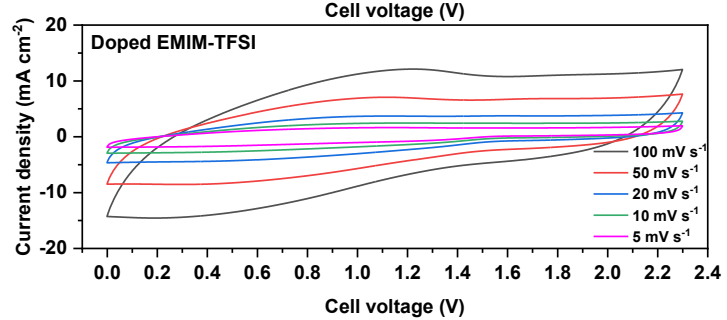

(e)

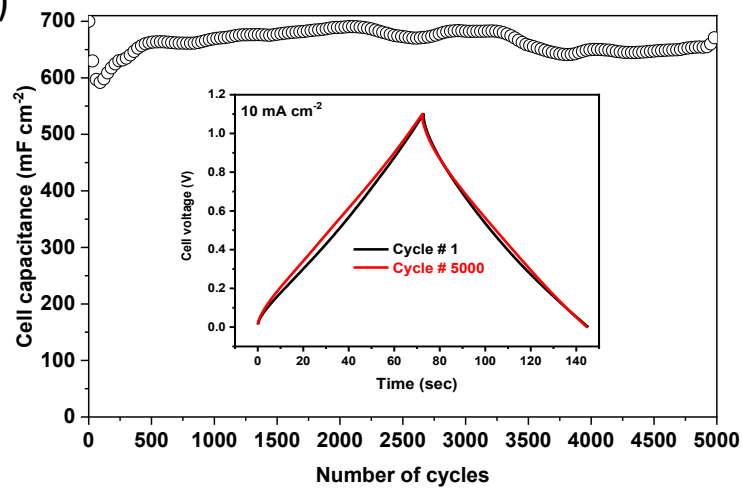

Figure 5. Characterization of an all-solid-state interdigitated micro-device based on porous $\mathrm{RuO}_{x} \mathrm{~N}_{\mathrm{y}} \mathrm{S}_{\mathrm{z}}$. (a) Schematic and (b) image of an interdigitated microsupercapacitor before encapsulation. (c) CVs in doped PVA at different scan rates. (d) CVs in doped [EMIM][TFSI] at different scan rates. (e) Cell capacitance retention with the number of charge / discharge curves at $10 \mathrm{~mA} \mathrm{~cm}^{-2}$. Inset: $1^{\text {st }}$ and $5000^{\text {th }}$ potential-time curve during GCD.

The microsupercapacitor exhibits a remarkable cell capacitance of $714 \mathrm{mF} \mathrm{cm}^{-2}$ at $5 \mathrm{mV} \mathrm{s}^{-1}$ in doped PVA (Figure 5c) with a very low equivalent series resistance (ESR) of $0.7 \Omega \mathrm{cm}^{2}$, as shown in the Nyquist plot (Figure S15). No leakage current is observed, with a near vertical straight line in the low-frequency region, as expected for a pseudocapacitive material. The delivered specific energy density achieves a value of $432 \mathrm{~mJ} \mathrm{~cm}^{-2}$, and a maximum power density of $421 \mathrm{~mW} \mathrm{~cm}^{-2}$. Using the doped [EMIM][TFSI], the cell voltage can be extended up to $2.3 \mathrm{~V}$ with no visible sign of electrolyte or electrode degradation (Figure 5d). Although this high voltage comes at the expense of a lower cell capacitance and higher ESR, the energy and power density reach in this case of $460 \mathrm{~mJ} \mathrm{~cm}^{-2}$ and $110 \mathrm{~mW} \mathrm{~cm} \mathrm{~cm}^{-2}$, respectively. The long-term behavior of the solid-state microdevice was tested by repeated galvanostatic charge/discharge cycles at a high current density of $10 \mathrm{~mA} \mathrm{~cm}^{-2}$ (Figure 5e). The device shows stable cycling performance with almost no loss of specific capacitance even after 5000 cycles, with identical symmetrical triangular curves for all cycles.

In summary, conformal deposition of $\mathrm{RuO}_{\mathrm{x}} \mathrm{N}_{\mathrm{y}} \mathrm{S}_{\mathrm{z}}$ on $3 \mathrm{D}$ porous current collectors with extremely high surface area has been reported through ambient temperature electrodeposition process. Extremely high capacitance of $>10 \mathrm{~F} \mathrm{~cm}^{-2}$ was obtained for supercapacitor performance with outstanding stability $>5000$ cycles. These porous electrodes also exhibited unrivaled performance as microbattery cathodes with high areal capacity $>5 \mathrm{mAh} \mathrm{cm}^{-2}$ at low rates and stability $>2000$ cycles, making it suitable for dual purposes applications - power delivery as well as energy delivery electrodes for microelectronics. These electrodes can sustain thousands of cycles of operations both in batteries and supercapacitors and are fabricated through facile simple electrodeposition strategy, which makes it ideal for integration with existing microfabrication procedures for different microsystems as well as for new upcoming applications in the IoT age. These electrodes can be further coupled with solid electrolytes or ionic liquids to enhance their lifetime, storage ability and electrochemical performance. They can also be envisioned in $3 \mathrm{D}$ stacked interdigitated configurations with appropriate counter electrode materials to provide excellent energy/power density microenergy solutions for novel microsystems seeking energy autonomy. 


\section{ACKNOWLEDGMENT}

D. Pech acknowledges the support from the European Research Council (ERC, Consolidator Grant, ERC-2017-CoG, Project 771793 3DCAP). D. Guay acknowledges the support of the Natural Science and Engineering Research Council (NSERC) of Canada. This work was supported by LAAS-CNRS technology platform, a member of Renatech network.

\section{REFERENCES}

(1) Nathan, M.; Golodnitsky, D.; Yufit, V.; Strauss, E.; Ripenbein, T.; Shechtman, I.; Menkin, S.; Peled, E. ThreeDimensional Thin-Film Li-Ion Microbatteries for Autonomous MEMS. J. Microelectromechanical Syst. 2005, 14 (5), 879-885. https://doi.org/10.1109/JMEMS.2005.851860.

(2) Pikul, J. H.; Ning, H. Powering the Internet of Things. Joule 2018, 2 (6), 1036-1038. https://doi.org/10.1016/j.joule.2018.06.005.

(3) Kyeremateng, N. A.; Brousse, T.; Pech, D. Microsupercapacitors as Miniaturized Energy-Storage Components for onChip Electronics. Nat. Nanotechnol. 2017, 12 (1), 7-15. https://doi.org/10.1038/nnano.2016.196.

(4) Lethien, C.; Le Bideau, J.; Brousse, T. Challenges and Prospects of 3D Micro-Supercapacitors for Powering the Internet of Things. Energy Environ. Sci. 2019, 12 (1), 96-115. https://doi.org/10.1039/c8ee02029a.

(5) Zhang, J.; Zhang, G.; Zhou, T.; Sun, S. Recent Developments of Planar Micro-Supercapacitors: Fabrication, Properties, and Applications. Adv. Funct. Mater. 2020, 30 (19), 1-21. https://doi.org/10.1002/adfm.201910000.

(6) Pan, X.; Hong, X.; Xu, L.; Li, Y.; Yan, M.; Mai, L. On-Chip Micro/Nano Devices for Energy Conversion and Storage. Nano Today 2019, 28, 100764. https://doi.org/10.1016/j.nantod.2019.100764.

(7) Ryu, H.; Yoon, H. J.; Kim, S. W. Hybrid Energy Harvesters: Toward Sustainable Energy Harvesting. Adv. Mater. 2019, 31 (34), 1-19. https://doi.org/10.1002/adma.201802898.

(8) Raj, A.; Steingart, D. Review—Power Sources for the Internet of Things. J. Electrochem. Soc. 2018, 165 (8), B3130B3136. https://doi.org/10.1149/2.0181808jes.

(9) Li, Q.; Zheng, S.; Xu, Y.; Xue, H.; Pang, H. Ruthenium Based Materials as Electrode Materials for Supercapacitors. Chem. Eng. J. 2018, 333 (September 2017), 505-518. https://doi.org/10.1016/j.cej.2017.09.170.

(10) Watanabe, E.; Ushiyama, H.; Yamashita, K.; Morikawa, Y.; Asakura, D.; Okubo, M.; Yamada, A. Charge Storage Mechanism of RuO2/Water Interfaces. J. Phys. Chem. C 2017, 121 (35), 18975-18981. https://doi.org/10.1021/acs.jpcc.7b02500.

(11) Simon, P.; Gogotsi, Y. Perspectives for Electrochemical Capacitors and Related Devices. Nat. Mater. 2020, 19, 11511163. https://doi.org/10.1038/s41563-020-0747-z.

(12) Lee, D. W.; Lee, J. H.; Min, N. K.; Jin, J. H. Buckling Structured Stretchable Pseudocapacitor Yarn. Sci. Rep. 2017, 7 (1), 1-8. https://doi.org/10.1038/s41598-017-12375-7.

(13) Brousse, K.; Pinaud, S.; Nguyen, S.; Fazzini, P. F.; Makarem, R.; Josse, C.; Thimont, Y.; Chaudret, B.; Taberna, P. L.; Respaud, M.; et al. Facile and Scalable Preparation of Ruthenium Oxide-Based Flexible Micro-Supercapacitors. $A d v$. Energy Mater. 2020, 10 (6), 1-9. https://doi.org/10.1002/aenm.201903136.

(14) Jiang, Q.; Kurra, N.; Alhabeb, M.; Gogotsi, Y.; Alshareef, H. N. All Pseudocapacitive MXene-RuO2 Asymmetric Supercapacitors. Adv. Energy Mater. 2018, 8 (13), 1-10. https://doi.org/10.1002/aenm.201703043.

(15) Choi, S. H.; Kim, J. S.; Yoon, Y. S. Fabrication and Characterization of SnO2-RuO2 Composite Anode Thin Film for Lithium Ion Batteries. Electrochim. Acta 2004, 50 (2-3), 547-552. https://doi.org/10.1016/j.electacta.2004.02.066.

(16) Gregorczyk, K. E.; Kozen, A. C.; Chen, X.; Schroeder, M. A.; Noked, M.; Cao, A.; Hu, L.; Rubloff, G. W. Fabrication of 3D Core-Shell Multiwalled Carbon Nanotube@RuO2 Lithium-Ion Battery Electrodes through a RuO2 Atomic Layer Deposition Process. ACS Nano 2015, 9 (1), 464-473. https://doi.org/10.1021/nn505644q.

(17) Yang, C.; Que, W.; Tang, Y.; Tian, Y.; Yin, X. Nitrogen and Sulfur Co-Doped 2D Titanium Carbides for Enhanced Electrochemical Performance. J. Electrochem. Soc. 2017, 164 (9), A1939-A1945. https://doi.org/10.1149/2.1091709jes.

(18) Zhao, Q.; Zhu, Q.; Miao, J.; Zhang, P.; Wan, P.; He, L.; Xu, B. Flexible 3D Porous MXene Foam for High-Performance Lithium-Ion Batteries. Small 2019, 15 (51), 1-9. https://doi.org/10.1002/smll.201904293.

(19) Ferris, A.; Garbarino, S.; Guay, D.; Pech, D. 3D RuO2 Microsupercapacitors with Remarkable Areal Energy. $A d v$. Mater. 2015, 27 (42), 6625-6629. https://doi.org/10.1002/adma.201503054.

(20) Ferris, A.; Bourrier, D.; Garbarino, S.; Guay, D.; Pech, D. 3D Interdigitated Microsupercapacitors with Record Areal Cell Capacitance. Small 2019, 1901224, 1901224. https://doi.org/10.1002/smll.201901224.

(21) Chen, L. Y.; Hou, Y.; Kang, J. L.; Hirata, A.; Fujita, T.; Chen, M. W. Toward the Theoretical Capacitance of RuO 2 Reinforced by Highly Conductive Nanoporous Gold . Adv. Energy Mater. 2013, 3 (7), 851-856. https://doi.org/10.1002/aenm.201300024.

(22) Hu, C.-C.; Huang, Y. Cyclic Voltammetric Deposition of Hydrous Ruthenium Oxide for Electrochemical Capacitors. J. Electrochem. Soc. 1999, 146 (7), 2465-2471. https://doi.org/10.1149/1.1391956.

(23) Hu, C. C.; Liu, M. J.; Chang, K. H. Anodic Deposition of Hydrous Ruthenium Oxide for Supercapacitors. J. Power Sources 2007, 163 (2), 1126-1131. https://doi.org/10.1016/j.jpowsour.2006.09.060. 
(24) Park, B. O. K.; Lokhande, C. D.; Park, H. S.; Jung, K. D.; Joo, O. H. S. Electrodeposited Ruthenium Oxide (RuO2) Films for Electrochemical Supercapacitors. J. Mater. Sci. 2004, 39 (13), 4313-4317. https://doi.org/10.1023/B:JMSC.0000033415.47096.db.

(25) Prataap, R. K. V.; Arunachalam, R.; Pavul Raj, R.; Mohan, S.; Peter, L. Effect of Electrodeposition Modes on Ruthenium Oxide Electrodes for Supercapacitors. Curr. Appl. Phys. 2018, 18 (10), 1143-1148. https://doi.org/10.1016/j.cap.2018.06.015.

(26) Jow, J. J.; Lee, H. J.; Chen, H. R.; Wu, M. S.; Wei, T. Y. Anodic, Cathodic and Cyclic Voltammetric Deposition of Ruthenium Oxides from Aqueous RuCl3solutions. Electrochim. Acta 2007, 52 (7), 2625-2633. https://doi.org/10.1016/j.electacta.2006.09.018.

(27) Augustyn, V.; Simon, P.; Dunn, B. Pseudocapacitive Oxide Materials for High-Rate Electrochemical Energy Storage. Energy Environ. Sci. 2014, 7 (5), 1597-1614. https://doi.org/10.1039/c3ee44164d.

(28) Muñoz-Rojas, D.; Casas-Cabanas, M.; Baudrin, E. Evolution of the Electrochemical Processes vs. Li in RuO2 as a Function of Crystallite Size. Solid State Ionics 2009, 180 (4-5), 308-313. https://doi.org/10.1016/j.ssi.2009.02.020.

(29) Balaya, P.; Li, H.; Kienle, L.; Maier, J. Fully Reversible Homogeneous and Heterogeneous Li Storage in RuO2 with High Capacity. Adv. Funct. Mater. 2003, 13 (8), 621-625. https://doi.org/10.1002/adfm.200304406.

(30) Wu, F.; Yushin, G. Conversion Cathodes for Rechargeable Lithium and Lithium-Ion Batteries. Energy Environ. Sci. 2017, 10 (2), 435-459. https://doi.org/10.1039/c6ee02326f.

(31) Delmer, O.; Balaya, P.; Kienle, L.; Maier, J. Enhanced Potential of Amorphous Electrode Materials: Case Study of RuO2. Adv. Mater. 2008, 20 (3), 501-505. https://doi.org/10.1002/adma.200701349.

(32) Perego, D.; Heng, J. S. T.; Wang, X.; Shao-Horn, Y.; Thompson, C. V. High-Performance Polycrystalline RuOx Cathodes for Thin Film Li-Ion Batteries. Electrochim. Acta 2018, 283, 228-233. https://doi.org/10.1016/j.electacta.2018.06.172.

(33) Haag, J. M.; Pattanaik, G.; Durstock, M. F. Nanostructured 3D Electrode Architectures for High-Rate Li-Ion Batteries. Adv. Mater. 2013, 25 (23), 3238-3243. https://doi.org/10.1002/adma.201205079.

(34) Dinh, T. M.; Achour, A.; Vizireanu, S.; Dinescu, G.; Nistor, L.; Armstrong, K.; Guay, D.; Pech, D. Hydrous $\mathrm{RuO} 2 /$ Carbon Nanowalls Hierarchical Structures for All-Solid-State Ultrahigh-Energy-Density MicroSupercapacitors. Nano Energy 2014, 10, 288-294. https://doi.org/10.1016/j.nanoen.2014.10.003.

(35) Eustache, E.; Tilmant, P.; Morgenroth, L.; Roussel, P.; Patriarche, G.; Troadec, D.; Rolland, N.; Brousse, T.; Lethien, C. Silicon-Microtube Scaffold Decorated with Anatase $\mathrm{TiO} 2$ as a Negative Electrode for a 3D Litium-Ion Microbattery. Adv. Energy Mater. 2014, 4 (8), 1-11. https://doi.org/10.1002/aenm.201301612.

(36) Eustache, E.; Douard, C.; Retoux, R.; Lethien, C.; Brousse, T. MnO2 Thin Films on 3D Scaffold: Microsupercapacitor Electrodes Competing with "Bulk" Carbon Electrodes. Adv. Energy Mater. 2015, 5 (18), 3-7. https://doi.org/10.1002/aenm.201500680.

(37) El-Kady, M. F.; Ihns, M.; Li, M.; Hwang, J. Y.; Mousavi, M. F.; Chaney, L.; Lech, A. T.; Kaner, R. B. Engineering Three-Dimensional Hybrid Supercapacitors and Microsupercapacitors for High-Performance Integrated Energy Storage. Proc. Natl. Acad. Sci. U. S. A. 2015, 112 (14), 4233-4238. https://doi.org/10.1073/pnas.1420398112.

(38) Zhang, H.; Shi, T.; Wetzel, D. J.; Nuzzo, R. G.; Braun, P. V. 3D Scaffolded Nickel-Tin Li-Ion Anodes with Enhanced Cyclability. Adv. Mater. 2016, 28 (4), 742-747. https://doi.org/10.1002/adma.201504780.

(39) Asfaw, H. D.; Tai, C. W.; Nyholm, L.; Edström, K. Over-Stoichiometric NbO2 Nanoparticles for a High Energy and Power Density Lithium Microbattery. ChemNanoMat 2017, 3 (9), 646-655. https://doi.org/10.1002/cnma.201700141.

(40) Robert, K.; Douard, C.; Demortière, A.; Blanchard, F.; Roussel, P.; Brousse, T.; Lethien, C. On Chip Interdigitated Micro-Supercapacitors Based on Sputtered Bifunctional Vanadium Nitride Thin Films with Finely Tuned Inter- and Intracolumnar Porosities. Adv. Mater. Technol. 2018, 3 (7), 1-12. https://doi.org/10.1002/admt.201800036.

(41) Chang, W. C.; Lu, S. P.; Chu, H. C.; Tuan, H. Y. Lithium-Ion Battery Anodes of Stacked Nanowire Laminate for Ultrahigh Areal Capacities. ACS Sustain. Chem. Eng. 2019, 7 (1), 156-164. https://doi.org/10.1021/acssuschemeng.8b02409.

(42) Robert, K.; Stiévenard, D.; Deresmes, D.; Douard, C.; Iadecola, A.; Troadec, D.; Simon, P.; Nuns, N.; Marinova, M.; Huvé, M.; et al. Novel Insights into the Charge Storage Mechanism in Pseudocapacitive Vanadium Nitride Thick Films for High-Performance on-Chip Micro-Supercapacitors. Energy Environ. Sci. 2020, 13 (3), 949-957. https://doi.org/10.1039/c9ee03787j.

(43) Jiang, Q.; Lei, Y.; Liang, H.; Xi, K.; Xia, C.; Alshareef, H. N. Review of MXene Electrochemical Microsupercapacitors. Energy Storage Mater. 2020, 27 (October 2019), 78-95. https://doi.org/10.1016/j.ensm.2020.01.018.

(44) Patnaik, S. G.; Jadon, A.; Tran, C. C. H.; Estève, A.; Guay, D.; Pech, D. High Areal Capacity Porous Sn-Au Alloys with Long Cycle Life for Li-Ion Microbatteries. Sci. Rep. 2020, 10 (1), 1-8. https://doi.org/10.1038/s41598-02067309-7. 